\title{
REFLEXIONES SOBRE LA EUTANASIA: ¿NUESTRA ELECCIÓN?
}

\author{
REFLECTIONS ON EUTANASIA: \\ OUR CHOICE?
}

Luz Marlene Montero Navincopa*

\section{Resumen}

El presente artículo busca abordar el tema de la eutanasia desde un enfoque humano con relevancia jurídica. Explicando qué es la eutanasia, conocida como muerte digna o suicidio asistido, que persigue que la persona enferma sin un pronóstico de recuperación, en una etapa terminal y que sufra mucho, pueda acabar su sufrimiento, poniendo fin a su vida para alivio propio. Asimismo, en qué casos podría aplicarse la eutanasia, tipos o formas de esta según su ejecución, analizando los beneficios y perjuicios de la misma, si esta es una decisión consciente y voluntaria dada la condición especial de salud de la persona que decide sobre poner fin a su vida, llevando su análisis a un plano existencial, religioso, económico, político, ético y natural, que nos permita finalmente contar con un panorama de conocimiento y reflexión que nos ayude a tomar una posición autónoma e informada sobre nuestro punto de vista sobre la eutanasia.

Palabras Clave: vida, muerte digna, libertad, conciencia.

\section{Abstract}

This article seeks to addres the issue of euthanasia from a human point of view with legal effects. Trying to explain what euthanasia do is, known as good death or assisted suicide, it persues that a sick person without a recovery forecast, in a terminal situation and who suffers a lot, could finish with all his suffering, puting an end to his own life for own relief. Then, in wich cases could euthanasia be apply, types, and forms according to the execution, analyzing the benefits and damage, if it is a voluntary and conscious decision, given the especial state of health of the person who decides to put an end to his own life, carrying the analysis to an existential, religious, economic, politic, ethical and natural plane, finally giving a full picture of

Juez Titular de Familia del Tercer Juzgado de Familia de San Juan de Lurigancho. Actual Juez Superior Provisional de la Sala Penal Liquidadora Permanente de SJL Corte Superior de Justicia de Lima Este Poder Judicial del Perú. 
kwowledge and thought to help us adopting a well informed and autonomous posture about our own point of view of euthanasia.

Keywords: live, dignified death, freedom, awareness.

\section{INTRODUCCIÓN}

Hablar de eutanasia siempre ha sido y será un tema polémico y controversial, pues la vida es lo que nos permite respirar, ver, hablar, escuchar, leer y sentir, como ahora, mientras que la muerte es la culminación de TODO.

Sin embargo, la eutanasia, no solo tiene que ver con la culminación de la vida, sino con aspectos especiales que la encuadran dentro de una serie de requisitos y puntos de vista, que la hacen muy cuestionable.

Como, ¿Quiénes somos nosotros para decidir sobre la vida?, incluso la nuestra, ¿Es correcto decidir sobre nuestra muerte?, sobre todo cuando lo que vivimos ya no es "vida", ¿Qué es lo "correcto"? ¿La dignidad es un derecho que prima sobre la vida?, ¿De qué nos sirve la dignidad, si no tenemos vida?

Creo que quien ha tenido cerca a una persona enferma, podría animarse a verter una opinión más autorizada que otros. Sin embargo, ¿qué hay de quien estuvo enfermo y sufriendo o a punto de morir, y su voluntad solo era seguir viviendo y aferrarse a la vida, tratando de pedir que lo ayuden a prolongar su existencia para seguir despertando cada día, pero no pudo decirlo?

A lo largo de la historia, desde muchísimos siglos atrás, incluso antes de Cristo, ya existía la eutanasia y también era discutida. Y es que, durante el desarrollo de la humanidad, por una causa u otra se han producido suicidios, ayudas para evitar el sufrimiento y discriminación, selección de la especie humana, con diferentes nombres, como la practicada por Hitler, al pretender exterminar a los ancianos y niños durante su gobierno.

No obstante, hoy en día el tema de la eutanasia se centra más "humanizadamente" en el significado de sus orígenes griegos, esto es, lo que se conoce como la "buena muerte", "muerte digna", "suicidio asistido" u "homicidio terapéutico". 


\section{ORIGEN ETIMOLÓGICO Y DEFINICIÓN}

No podemos dejar de recurrir a la definición etimológica, pues como todo origen, se remonta a uno griego o latín; en este caso, tenemos que la doctrina confluye en que eutanasia está compuesta por dos vocablos griegos, "Eu", que significa "buen" y "Thanatos", que significa "muerte", de cuya composición original podemos deducir que se trató de representar la "buena muerte" o "muerte dulce", evitando el sufrimiento intolerable de una persona que no tiene mayores esperanzas de vivir.

¿Pero cómo podríamos definir la eutanasia hoy en día? La eutanasia, a nivel mundial, implica un significado auxiliador y aliviador, de remedio para quien se aventure a decidir acabar con su vida, pero no en cualquier caso, sino en casos claramente establecidos, como cuando existiera un sufrimiento extremo.

Así, la Real Academia de la Lengua Española, define la eutanasia como la "Intervención deliberada para poner fin a la vida de un paciente sin perspectiva de cura. (...)". Y, la Organización Mundial de la Salud, la define como: "aquella acción del médico que provoca deliberadamente la muerte del paciente".

A estas habría que agregarle, que la decisión tendría que ser la más beneficiosa para el peticionante, vale decir tendría que ser pedida por quien sufre una enfermedad terminal, para poner fin a su sufrimiento como única y última opción, porque su dolor es insoportable y la muerte resulta ser la mejor solución.

De ahí su origen griego de "buena muerte".

\section{TIPOS DE EUTANASIA}

A estas alturas de "evolución" de la humanidad y de la ciencia, la eutanasia también ha evolucionado y quienes se han dedicado a hacer un estudio de ella, sea para defenderla $u$ oponerse, cuando menos coinciden en que su ejercicio está orientado a poner fin a la vida humana, a efectos de acabar con el sufrimiento insoportable que podría padecer una persona como consecuencia de una enfermedad incurable y en etapa terminal.

Y, dependiendo de la forma en que se ejecute o según como se realice la aplicación de la eutanasia, podríamos clasificarla desde diferentes perspectivas, donde podríamos distinguir por ejemplo su clasificación según 
la voluntad de quien la solicita, la voluntaria o involuntaria; según la acción, pasiva o activa; según el móvil que te conduzca a ella compasiva o económica; según quien la ejecute, autónoma o heterónoma, entre otras que veremos a continuación.

La eutanasia voluntaria es aquella en el que está presente la voluntad del sujeto a someterse a su muerte y en la que este se encuentra en posibilidad de expresar su voluntad para hacerlo; como es el caso de los enfermos que se encuentran padeciendo de alguna enfermedad incurable y para cuyo mal no exista salvación en este mundo, pero que se encuentra consciente de su mal y no ha perdido contacto con el mundo ni con la realidad, vale decir que se encuentra en pleno uso de sus facultades mentales y civiles.

Mientras que en el caso de la eutanasia involuntaria, el caso es distinto, pues aquí el sujeto a someter a eutanasia no se encuentra conectado con el mundo, al menos no para la ciencia médica, sino que ha sufrido un daño cerebral tan grave y severo que difícilmente se piensa saldrá del coma en que se encuentra y por lo tanto, no podrá expresar su voluntad respecto a someterse a la eutanasia o no; sino que serán sus familiares más cercanos quienes decidirán si ésta se aplicaría o no a su paciente que ya no tiene esperanza de vida.

Por otro lado, según la forma de aplicación de la eutanasia o según su ejecución, tenemos que ésta se puede clasificar en activa y pasiva.

La eutanasia activa es aquella en la que se ejecuta un acto para que ésta (la muerte) se produzca, esto es, existe la participación de un profesional que realizará una acción para poner fin al sufrimiento de su paciente, que sufre un mal incurable y cuyo dolor resulta intolerable e innecesario padecer, la que se podría ejecutar a través de una inyección de sueño, desconexión de aparatos, respiradores, entre otros, que estuviesen facilitando la vida de la persona a someter a eutanasia.

En cuanto a la eutanasia pasiva, ésta es también conocida como muerte natural o eutanasia por omisión, por cuanto en este tipo de eutanasia no existe la intervención de alguien, ni para acelerar la muerte, ni para prolongar la vida, consiste en dejar que la persona muera sin prestarle el auxilio necesario, dejando finalmente que deje de existir sin prestarle ningún tipo de apoyo.

Asimismo, según la motivación o móvil que conduzca a la eutanasia se puede distinguir la compasiva o económica. 
Siendo la compasiva la solicitada o generada por la familia de la persona que padece el "sufrimiento", a efectos de que ésta deje de soportar el gran dolor o padecimiento por su condición de salud o física, movidos básicamente por un sentimiento de compasión por su familiar o la propia persona, si está en condiciones de hacerlo.

Mientras que la económica, busca cesar el padecimiento pero movida por los gastos que genera mantener la prolongación de la vida de una persona enferma, a efectos de ahorrar en la inversión de cuidados, medicinas, equipos y gastos en general que ocasiona esa prolongación de la vida.

Otro criterio de clasificación es según quien la ejecuta, vale decir según el que ejerce la acción, así tenemos que esta podría ser autónoma o heterónoma.

Autónoma, cuando el que realiza la acción es la misma persona sobre la que se ejecuta el acto, esto es, la persona que viene sufriendo el estado de padecimiento es la misma que pone fin a su vida, que en algunos casos es también conocida como suicidio asistido.

$\mathrm{Y}$, heterónoma, cuando es un tercero, una persona diferente a la que se le va a practicar la eutanasia la que ejecuta el acto, que según los países en que es permitida, tendría que ser un médico.

Asimismo, a manera de ampliar estas clasificaciones, tenemos la clasificación histórica, discriminadora o selectiva, que es la que recoge la historia de la humanidad, cuando, por ejemplo, se habla de la época espartana, donde se sacrificaba a los niños que nacían con alguna malformación congénita, lanzándolos desde una alta montaña conocida como el monte Taigeto. Así como la practicada por Adolfo Hitler, en Alemania, quien cesaba la vida de personas que no se encontraban en condición de superioridad por cuestiones de raza, según su filosofía.

Desde el enfoque, médico, jurídico, ético o el sentido común, encontraremos diversos tipos de clasificaciones sobre la eutanasia, pero el tema no queda ahí.

Y, en este punto, sería conveniente mencionar, que una de las variantes de eutanasia, es la que se conoce con el nombre de suicidio asistido, aunque algunos no la consideren propiamente un tipo de eutanasia, muy relacionado con la eutanasia activa y autónoma, haciendo la diferencia que 
si bien es cierto están vinculados, por cuanto, a través de ambos (suicidio asistido y eutanasia activa) se pone fin a la existencia de un ser humano, en el primer caso (suicidio asistido) no interviene un tercero como en el caso de la eutanasia activa, sino que en este caso se le brinda al paciente orientación y los medios necesarios para que él mismo pueda terminar con su propia vida, no siendo, por lo tanto, lo mismo, aunque para algunos podría parecerles muy similar. Por ello, la eutanasia autónoma, también resulta un tipo de eutanasia impropia, pues tampoco interviene un tercero (médico), aunque para nosotros resultan ser variantes de una misma vertiente.

Otro punto que me gustaría desarrollar, es el tratamiento paliativo, pues quienes se encuentran del lado de la eutanasia cuestionan el sufrimiento intenso y el que la vida de las personas, aun no padeciendo dolor, se torne indigna. Sin embargo, según la perspectiva médica y el propio fin de su profesión es brindar la mejor calidad de tratamiento y de vida, buscando justamente evitar el dolor y el sufrimiento de sus pacientes a través de tratamientos paliativos, que tienen como propósito evitar que el paciente sufra los estragos de una enfermedad dolorosa.

Medicamentos que han sido desarrollados con este propósito para calmar los estragos de los cuadros clínicos en etapa terminal. Así como, también se ha desarrollado tecnología que permite que una persona pueda ser lo más independientemente posible a través de sillas de rueda o computadoras que faciliten la comunicación y movimiento de quienes padecen algún tipo de inmovilidad.

Todo ello buscando la mejor calidad de vida y no de muerte.

\section{MI VOLUNTAD O LA TUYA}

Hemos visto los diferentes tipos de clasificación sobre la eutanasia y les aseguro que si se interesan más por el tema van a encontrar una clasificación mucho más diversa y amplia que la que he recogido, pero lo que pretendo con este artículo es expresar más que un conocimiento teórico, práctico o ético de lo que es la eutanasia, el reflexionar sobre lo que sé de ella, para que luego de la lectura ustedes puedan tener sus propias reflexiones.

La eutanasia, implica ponerle fin a la vida de un enfermo terminal, cuya salud ya no tiene remedio y su condición de vida y dolor es tal que es mejor que muera y deje de sufrir. 
Quienes están a favor de la eutanasia, señalan que este es el derecho a morir dignamente y que si bien no está previsto como tal, tendría que al menos no ser sancionado para quien decida ejercerlo. Más o menos esa es la lógica de los defensores.

Profundicemos un poquito más. Quienes defienden la eutanasia, estarían luchando porque dentro de los derechos protegidos de los seres humanos, también se considere el de la muerte, pero no cualquier muerte, sino una digna o priorizando la dignidad de su titular, que finalmente la dignidad - sí es un derecho constitucionalmente reconocido en todas las constituciones del mundo.

En ese sentido, tendríamos que las personas que se encontrasen sufriendo, sin tener una adecuada calidad de vida y sintiesen afectada su dignidad, deberían poder elegir dejar de vivir, porque ello a su vez les resultaría más digno que su propia vida en esas condiciones.

Sin embargo, esta elección de dejar de sufrir, tendría que estar encuadrada en los supuestos como (1) el que no existan otras posibilidades de expectativa de vida desde el punto de la ciencia médica, (2) que la vida de la persona que desea someterse a la eutanasia sea tan intolerable por el cuadro clínico que atraviesa, como sufrir de dolores que hagan insoportable su propio vivir, (3) que su condición de vida le haga desear acabar con esta.

Y, pienso, en si una persona que esté atravesando un cuadro como uno de los mencionados en el párrafo anterior ¿estaría en condiciones de decidir sobre acabar con su vida? o ¿su conciencia y voluntad estarían afectadas?

He escuchado de personas que han tenido parientes que han padecido enfermedades muy difíciles y han llegado a una etapa terminal, pero nunca he escuchado ni he visto insinuar que se debería acabar con la vida del enfermo.

Asimismo, he trabajado con personas que han tenido la enfermedad tan terrible y dolorosa como es el cáncer, y por el contrario he sido testigo de cómo han luchado por sus vidas hasta el último día, tratando de trabajar con normalidad, implorando a los médicos que las asistan y las ayuden a seguir viviendo. Entonces, surge en mí la duda, de quien decide en la aplicación de la eutanasia. 
¿Es la persona cuyo transcurrir de su vida se tornó tan intolerable e indigna que pide su propia muerte o es la familia la que finalmente terminará decidiendo cuándo, cómo y dónde se pondrá fin a la vida de su ser querido?

Sé que hay personas que han decido conscientemente sobre el fin de su vida, pero no todas las realidades son las mismas.

Aquí también nos corresponde analizar, ¿qué tan consciente se encuentra una persona que viene padeciendo un cuadro de inconsciencia y preguntarnos, si está inconsciente, está sufriendo? Y ¿es necesario matarla o someterla a la eutanasia para acabar con su sufrimiento? Entonces ¿sería una muerte digna para el enfermo o una muerte salvadora para la familia?

Entonces, nuevamente nos preguntamos, ¿Quién decide? ¿Para quién es la muerte digna? Si la persona que sufre su postración no siente o está inconsciente, si no tenemos forma de saber qué es lo que piensa y siente ¿la voluntad de acabar con una vida bajo estas circunstancias es la del sujeto sobre la que recaerá la eutanasia o la de la familia? ¿Qué debería proteger el Estado? ¿La muerte digna de quien no sabemos si quiere seguir viviendo o la muerte digna de quien vemos y suponemos que quiere morir porque la vemos en una cama o conectada a un respirador y la familia o ajenos piensa que debe morir para evitar su sufrimiento? ¿Quién decide si no se puede exteriorizar con conciencia y voluntad de forma expresa?

\section{EUTANASIA Y MORAL: BENEFICIOS Y PERJUICIOS}

Seguramente me quedo corta en mis descripciones, pues no conozco todas las realidades y formas de pensar, pero definitivamente sí puedo afirmar que es un tema controversial y sumamente discutido en el propio campo médico, al ser un tema íntimamente ligado a dicha área, pero para nada ajeno a las leyes y menos para la moral.

Y, es que todo lo humano va íntimamente ligado a lo legal y jurídico, pero sobre todo la moral, en nuestra vida, que es lo que justamente nos ocupa en este desarrollo.

El derecho fundamental y especialmente protegido por excelencia ha sido la vida; sin embargo, hoy en día este derecho indiscutible, maravilloso y excelso se ve cambiado por su oponente natural, que es la muerte. La 
muerte, que amparada o cubierta por un manto de licitud apelando a la dignidad, se ha traído a colación para ser incluido en algunas legislaciones incluso a nivel constitucional, como es el caso de nuestra cercana vecina Colombia.

La eutanasia, es una elección voluntaria o involuntaria, que puede ser producida o no (activa o pasiva), para sobreponer una muerte digna a una vida, no digna o poco digna, no se ha dicho con exactitud. Entonces, si cada uno en su lecho de enfermedad, tuviera que decidir acabar con su vida ¿el Estado tendría que respetar su decisión, pensando que es nuestra vida y nosotros debemos tener derecho para acabar con ella.?

¿Qué ocurriría si, al legalizarse la eutanasia o despenalizarse la misma de forma mayoritaria, el enfermo no desea morir y se aferra a la vida, como lo es por naturaleza incluso animal, instintivamente, y es la familia que, por falta de tiempo, falta de amor, falta de dinero, falta de voluntad para cuidarlo, desea acabar con la vida de su familiar encontrándose éste, consciente o no? ¿Podría acaso ocurrir que la persona enferma en una etapa terminal resulta un estorbo para la continuación de la vida del resto de la familia y todos convienen en que es mejor ponerle fin a este sufrimiento, pero no del enfermo, sino de la familia que lo cuida? ¿Resultaría ello moral?

¿Qué pasa en los supuestos en que se persigue acabar con un sufrimiento de quien no se sabe si siente o no? Y, aquí me voy a permitir hacer una confesión personal, aunque creo que no está permitido hacer referencias personales, pero considero que la experiencia es ilustrativa: recurrí a un tópico en una clínica por un tema muy simple de una uña, en realidad dos, y todo estuvo muy bien, hasta cuando el médico terminó y me dejó con las enfermeras, que fue cuando me empecé a sentir extraña y de pronto empecé a perder movilidad en el cuerpo, no podía hablar, no podía moverme, las personas corrían y se desesperaban por mí, y terminé en emergencia, pero mientras que yo no podía hablar, escuchaba todo el alboroto y solo pensaba en mi familia y rogaba a Dios que me diera otra oportunidad.

Las personas que se encuentran postradas en una cama de hospital o en sus casas, no necesariamente desean morir o están sufriendo, podría ser que por el contrario, aún en la condición en que se encuentran se aferran a la vida y son felices de escuchar sus voces y sentir su afecto, la ciencia no ha 
descubierto aún si esa condición de incomunicación o estado de inconsciencia o inamovilidad de una persona, es sinónimo de falta de calidad de vida, porque la vida es de cada quien. No hemos decido vivir, pero es nuestro derecho natural y aun así cuando la vida para otros podría parecer triste, aún en la pobreza, en la desigualdad, con capacidades diferentes, ¿el ser humano merece morir? o ¿tener derecho a decidir sobre su muerte?

Quizá podría resultar beneficioso para una familia ocupada y pobre o desocupada y rica, en cualquiera de los casos, independientemente del tema social o económico, lo que está en juego es una vida humana. Podríamos pensar que la familia ocupada es adinerada, pero no tiene tiempo para dedicarse a cuidar un enfermo y este tendría que ser asistido por una enfermera que velara por él, como lo vimos en una película, pero podría tratarse de una familia que tuviera todo el tiempo para dedicarse al cuidado de su enfermo, pero sin recursos para solventar los gastos, igualmente pensaríamos que ¿es justo que se acabe con la vida de este ser humano, pobre e indefenso? Igualmente, se trata de una vida.

Entonces no hay razón para discriminar o hacer diferencias entre un estrato social u otro, entre tiempo o dinero, sino en amor y vida, en voluntad y respeto, en independencia y gozo.

El beneficio no es para el resto. Se trata del respeto a una supuesta muerte digna para el que padece de una enfermedad incurable y un sufrimiento insoportable que hace su vida desdichada, ¿pero es acaso esta la solución? ¿Para quien sería el beneficio y para quien el perjuicio? Aún no lo sé.

\section{EUTANASIA Y RELIGIÓN}

Si para un médico esta idea es abominable, al menos en su mayoría, para un Sacerdote lo es aún más.

Y, es que, para la religión, la vida es un regalo de Dios y si esta es un regalo, ¿correspondería despreciarlo?

Este es un enfoque muy interesante, pues, aunque seamos creyentes o no, tenemos que coincidir en que ¿la vida nos fue dada? Si desean pueden dudarlo, pero esta maravilla de ser y existir, definitivamente es un regalo y eso no lo podemos negar, al menos eso pienso de mi vida. 
Y, si un regalo nos halaga y nos alegra, ¿por qué desecharlo? Alguien podría responder que es porque no nos hace feliz. Voy a tomar ese dicho y le replicaría diciendo: ¿Qué haces cuando un regalo no te hace feliz?, ¿lo desprecias, lo regalas, lo tiras, lo devuelves o lo conservas?

No sé ustedes, pero no conozco a alguien que haya despreciado, tirado o devuelto un regalo y menos en la cara de quien te lo regaló.

Quienes, no creen en Dios, piensan que después de la vida no hay nada y es menos difícil pensar en la muerte, pero ¿no creer en Dios te licencia para morir y decidir poner fin a tu vida o la de una persona que depende de ti?

El artículo escrito por Javier Vega Gutiérrez "Eutanasia: Concepto, tipos, aspectos éticos y jurídicos. Actitudes del personal sanitario ante el enfermo en situación terminal", recoge este punto de las convicciones religiosas, diciendo lo siguiente:

Las convicciones religiosas son el factor que influye de modo más determinante en las actitudes ante la propia muerte. Así hemos encontrado, que el miedo a tener una muerte dolorosa es menor en los que practican varias veces por semana. También que, a medida que la práctica religiosa es más frecuente, más de acuerdo se muestran los encuestados en que sus convicciones les ayudarán a aceptar los sufrimientos de una enfermedad mortal y que cuanto menos se practica más aumenta el deseo de que la muerte sea algo rápido.

En la práctica, la totalidad de los encuestados considera importante el estudio de los aspectos éticos de la atención médica, de los enfermos terminales y de otras cuestiones de ética profesional durante la carrera. Les parece muy importante al 66,2\% de los D.U.E. (Vega Gutiérrez, J. p. 8).

Aspecto, que ilustra que las personas que tienen fe, se encuentran más llenas de fortaleza que les provee su fe, la que ayuda a sostener sus dolores y sufrimientos, incluso con tranquilidad y sosiego enfrentando los dolores de su enfermedad y las dificultades que se les presente.

Leía hace algún tiempo que antes la vida, los nacimientos e incluso la muerte se vivía en compañía familiar y asistencia religiosa, la que facilitaba el trance del sufrimiento y dolor; sin embargo, hoy tanto el nacimiento como 
el sufrimiento por una enfermedad transcurren en los fríos pasadizos de un hospital o una clínica, pero igualmente en esos lugares la ayuda religiosa hace más tolerable el sufrimiento y consuela la existencia.

La iglesia, al menos católica, no admite la eutanasia y aunque algunos defensores señalan que incluso el Papa Juan Pablo II se sometió a una al dejarse morir por falta de asistencia médica (eutanasia pasiva), la iglesia lo niega, pues el Papa Peregrino no realizó ningún acto que ocasionara su muerte.

Por lo tanto, deduciríamos dos cosas: (1) que para la iglesia la eutanasia pasiva no es eutanasia, pues la persona no realiza ninguna acción para causar su muerte, solo se deja morir de manera natural y (2) la voluntad de morir sin acelerar la muerte se debe respetar.

Quienes creemos en Dios, tenemos esa fortaleza de fe y soporte emocional que nos brinda el consuelo especial para aferrarnos a la vida, respetarla y cuidarla; sin embargo, como personas formadas en derecho, también somos respetuosas del ideal que tiene cada uno desde su dogma de fe, sin perder la objetividad que nos da la ciencia del derecho para opinar sobre el tema a nivel jurídico.

Es por ello, que dentro de este artículo no podíamos dejar de incluir un enfoque religioso que seguramente se queda corto, sobre todo para la Universidad Femenina del Sagrado Corazón, de visos religiosos que seguramente espera una defensa más férrea de la vida desde el punto de vista religioso, pero no quiero resultar parcial en mi análisis, sino por el contrario mantener el punto de vista objetivo en él para facilitar al lector su propia decisión.

\section{LA EUTANASIA DESDE EL PUNTO DE VISTA MÉDICO Y ÉTICO}

No obstante lo vertido líneas arriba, la eutanasia no resulta ser un tema tan sencillo, ni netamente médico o aisladamente jurídico, pues por ser uno directamente vinculado al derecho madre, la VIDA, y más específicamente al término de ella, éste resulta ser un tema ardorosamente polémico.

Primeramente, tenemos que tener en claro que la eutanasia es un asunto en el que tienen injerencia los distintos planos de la vida social, política, jurídica, eclesiástica, médica y ética, quizá el más fuerte de todos, 
por la injerencia transversal que tiene en todos los aspectos del desarrollo y desenvolvimiento humano.

Si bien es cierto, para muchos la eutanasia no deja de ser considerada una ayuda necesaria y una escapatoria benigna, para quienes padecen enfermedades incurables, siendo así considerada en los países en que es legalmente permitida, para evitar los terribles dolores de un mal agobiante a un paciente o para cesar una vida "indigna" sujeta a un aparato que tan sólo brinda ventilación artificial, que resulta atormentador en muchos casos para los familiares, donde tanto pacientes como familiares ven a la eutanasia como una gran salida, existen muchas más posiciones o enfoques más que analizar al respecto.

Un estudio realizado por un grupo de profesionales españoles, Nombela, López, Serrano et al (2008 p.10), justamente desde un enfoque ético, señalaban que "(...) Hay que deslindar lo que puede ser el análisis de casos específicos, de lo que debe ser un principio irrenunciable, nadie tiene derecho a provocar la muerte de un semejante gravemente enfermo, ni por acción ni por omisión (...)", lo que me lleva a reafirmar que el valor de la vida y el respeto por la misma tendrían que estar por encima de todo, aún cuando existan mil motivos para justificar el corte de esta aduciendo un sufrimiento, pues siempre existirá esperanza de salvar una vida, de extender la misma, de hallar una cura. Y, más aún si esta decisión tuviera que ser tomada por un tercero que decidiera sobre nuestra existencia.

Esta intervención médica para causar la muerte digna resulta sumamente controversial sobre todo para los galenos - médicos, pues todo médico se forma para velar por la salud y cuidar de la vida, por lo que el solicitársele la muerte de un paciente, va en contra de su propia formación y razón de ser, transgrediendo su esencia de defender la vida, su prohibición de matar o dejar morir lo que resulta inconcebible y totalmente anti ético.

Como lo recoge Ausín y Peña (1998), citando a Peter Singer (1997), en su obra "Repensar la vida y la muerte. El derrumbe de nuestra ética tradicional":

¿Cuándo morimos entonces realmente? Parece difícil descubrir el momento en que se produce la muerte ya que, como resaltaremos, la muerte es más bien un proceso, no un fenómeno discreto. Por tanto, el nivel que elijamos para denominar lo que es la muerte es una decisión convencional, evaluativa. Así, Singer concluye que la muerte 
cerebral es una ficción práctica porque nos permite salvar órganos para trasplantes que si no se desperdiciarían y autoriza a suprimir un tratamiento cuando esté resultando inútil. Sin embargo, este tipo de consideraciones atentan directamente contra el principio absoluto de que toda vida humana es sagrada. (p. 4).

¿Cómo podría entonces procederse a la eutanasia "legalmente"? ¿teniéndose en consideración que solo la puede ejecutar un médico, certificando el sufrimiento intolerable de su paciente y procediendo a su eliminación? o ¿facilitando la orientación y el medicamento?, si esta constituye una conducta totalmente anti ética desde el punto de vista médico. Sigue siendo un aspecto polémico.

Sin embargo, pienso que ninguna norma legal podrá obligar al médico a condicionar o renunciar a sus principios éticos es decir a su integridad. Porque como sabemos, las normas legales son expresión de un momento o circunstancia política, social o económica, por lo tanto, pueden ser cambiantes de acuerdo al tiempo o las circunstancias que primen en ese momento; Por el contrario, los principios y normas éticas tienen una trascendencia mayor en la integridad de las personas.

Por ello, tanto el médico como el paciente están obligados a respetar la integridad de la otra persona y ninguno puede imponer sus valores al otro. (Rodríguez Casas, Rómulo César, 2001 p. 3)

Por tanto, primaría la ética médica, salvo que su posición sea contraria.

\section{LA EUTANASIA COMO POLÍTICA DE ESTADO}

La eutanasia o buena muerte, como una medida política o como una decisión a tomar por el Estado, a través de la aprobación de una ley autoritativa, para quienes decidieran acabar con su vida evitando sufrir los dolores de una enfermedad incurable, es otra posibilidad a tener en cuenta.

Ya hemos visto someramente la aplicación de ésta en algunos de los países en que se ha adoptado la medida, pero analicemos que sucedería si ésta se aprobara en una sociedad como la nuestra, en que los tratamientos para enfermedades que inevitablemente desencadenaran en una prolongada agonía, resulta sumamente onerosa, donde los tratamientos de estas enfermedades, aun cuando exista voluntad de seguir con ellos, se convierte 
en algo inalcanzable, ¿qué riesgos son los que podría desencadenar?, ¿cabría la posibilidad de autorizar la práctica de la eutanasia bajo esa perspectiva?.

Ante esa preocupante o tal vez aterradora, pero encubierta realidad, ¿se justificaría la aprobación de la eutanasia? De aprobarse ésta, ¿bajo qué parámetros se haría?

Para responder esas preguntas tendríamos que respondernos primero otras, como ¿sería constitucional aprobar una opción como la eutanasia en nuestro medio, como una alternativa para enfermos terminales o con enfermedades incurables, cuando de antemano sabríamos a quienes potencialmente estaría dirigida la opción, que tal vez resultaría aún más violatoria y discriminatoria que la situación actual?, convirtiéndose en una autorización para matar.

De esta forma, tendríamos que pensar en el miedo natural que podría invadir a los pacientes que amen la vida y que aun padeciendo una enfermedad que tal vez pudiera convertirse en un largo sufrimiento, desean seguir viviendo y gozando de cada amanecer y prolongar lo más que puedan sus días, los que podrían sentirse anímicamente perdidos y acabados al pensar en la posibilidad palpable de que su médico le propusiera someterse a una eutanasia.

Sin olvidar que podría convertirse en una puerta abierta de fácil acceso para todos aquellos que no desean seguir con el cuidado de sus pacientes, facultándoseles terminar con la vida de sus familiares aun en contra de su voluntad, pues sería permitido.

¿No vulneraría ello la libertad personal de elección de los pacientes, aun cuando ellos mismos estuvieran de acuerdo con someterse a una eutanasia, pues tan sólo tendrían ese camino en sus vidas sin otra opción a elegir?

No obstante que el tema de la eutanasia, para la mayoría de Estados en los que se encuentra legalmente permitida, ha sido un tema hartamente discutido y polemizado, no deja de ser uno que debe seguir tratándose con pinzas, por cuanto no solamente se trata de dictar una Ley autoritativa que aprobara la aplicación de la eutanasia, por cuanto no solamente se trata de dictar una que aprobara su aplicación, en el supuesto que se pensara en un probable proyecto de ley, exigiendo los requisitos que se consideren necesarios para una oportuna y correcta aplicación, sino que previamente sería necesario trabajar para la elaboración de una cultura eutanásica, así 
como prever tratamientos menos costosos para todos los enfermos por igual, para no dejar la opción sin más salidas, tan solo para quienes no pudieran seguir un tratamiento largo y costoso para alargar su vida.

Posiblemente la eutanasia podría convertirse en una buena opción, cuando todos tuvieran una real igualdad de acceso a las oportunidades y alternativas. Mientras tanto, en nuestro país no resulta lícito matar un paciente, tampoco es lícito negar a un paciente la prestación de cuidados vitales sin los cuales seguramente moriría.

Es necesario brindar al paciente todo tipo de tratamiento para mitigar sus dolores y prolongarle sus posibilidades de vivir y nunca resulta lícito cortar la vida de un paciente, aunque se mantenga en vida artificial.

Sin duda alguna, el tema de la eutanasia tanto a lo largo de la historia como hasta hoy, ha sido y seguirá siendo un tema ardorosamente polémico para toda sociedad, aún en las que ésta está legalmente permitida, y merece ser tratado y difundido con cautela y propiedad.

Existen muchos casos que se hicieron virales sobre personas que demandaban de sus Estados la autorización de una muerte digna o la despenalización de la eutanasia, como el caso de la norteamericana Brittany Maynard, quien al tomar conocimiento de que sufría de cáncer al cerebro en etapa muy avanzada, decidió mudarse junto con su familia de California al Estado de Oregon, donde está permitida la eutanasia, para poder poner fin a su vida conforme a su voluntad. Así también el caso de María José, de 61 años, una Española que fue cuidada por su esposo por muchos años, quien grabó un video donde ella refiere que le gustaría que le ayudaran a morir, recibiendo dicha ayuda de su esposo. Hace poco, en el Perú, el tema de la eutanasia se hizo público a través de la entrevista que realizó un canal de televisión a Ana Estrada, una Psicoterapeuta de 42 años, que sufre una enfermedad degenerativa y depende de la atención permanente de una enfermera, ella demuestra una alegría y vitalidad contagiantes, a través de su sonrisa; sin embargo, solicita la muerte.

Casos como estos son los que nos hacen reflexionar desde los distintos enfoques y perspectiva sobre la eutanasia.

Aunque tal vez en el presente artículo no podamos extendernos en el tema en su total magnitud, es necesario que precisemos los aspectos fundamentales 
sobre ella, que nos permita más adelante poder verter una opinión con conocimiento de causa, acerca de nuestra posición sobre la eutanasia

\section{CONDICIÓN LEGAL EN EL MUNDO}

En la actualidad, en algunos países, la eutanasia es legalmente permitida, como en Holanda, Bélgica, Luxemburgo, Colombia y Canadá.

Siendo Holanda el primer país en el mundo en legalizar la eutanasia, la que entró en vigencia en el año 2002. Teniendo como conducta autorizada la entrega de sustancias que puedan conducir a la muerte del paciente.

Esta legislación requiere del médico, que este cuente con el consentimiento consciente e informado del paciente y que el paciente padezca de una enfermedad sin cura y de dolores insoportables. Siendo un requisito adicional el contar con una segunda opinión médica en el mismo sentido.

Asimismo, Bélgica, fue el segundo país, en legalizar la eutanasia desde el año 2002, requiriendo, igualmente, la certificación de más de un médico.

Las tres principales condiciones que deben darse para que pueda llevarse a cabo son: una petición realizada de forma reiterada, cuidadosa y voluntariamente por un paciente competente, sin ninguna presión externa; un sufrimiento físico o mental insoportable (hay que señalar que son conceptos de valoración subjetiva por parte del paciente dado que el dintel del sufrimiento es algo individual y variable); y una lesión o condición patológica grave e incurable causada por enfermedad o accidente, por la cual el paciente se encuentra en una condición médica sin esperanza, no necesariamente terminal (a destacar que la ley no recoge un listado concreto de afecciones o patologías). Si alguno de estos requisitos no se cumple adecuadamente, el profesional o persona que ponga fin a la vida del paciente, será castigado por el Código Penal.(Grífols i Lucas, 2016 p. 37). (El resaltado es nuestro).

Asimismo, dicha práctica eutanásica ha sido ampliada respecto de menores de edad, siguiendo los pasos de Holanda, convirtiéndose así en el primero en ampliarlo sin considerar límites de edad.

Lo que a mi entender resulta una desprotección al derecho de decidir de los menores, que inicialmente no tienen capacidad de ejercicio por su 
propia indefensión e inmadurez, propias de su edad. Y, seguidamente, su condición anímica, quizá desmotivada y de dependencia absoluta de sus padres y médicos, tanto en atención, cuidados, como económicamente, que los colocan en una situación totalmente desventajosa para tomar una decisión sobre poner fin a su vida o que lo decidan por ellos.

Sin embargo, esta lista fue en aumento, cuando en el 2009, se unió a este conjunto Luxemburgo, sometiendo incluso su Constitución a modificación para permitir la eutanasia, recogiendo en su legislación el modelo Belga.

En América Latina, es Colombia, la que se convirtió en el primer país que introdujo la eutanasia en su Constitución. Sin embargo, ya traía un antecedente desde la sentencia dictada por su Corte Constitucional en 1997:

El consentimiento del sujeto pasivo debe ser libre, manifestado inequívocamente por una persona con capacidad de comprender la situación en que se encuentra. Es decir, el consentimiento implica que la persona posee información seria y fiable acerca de su enfermedad y de las opciones terapéuticas y su pronóstico, y cuenta con la capacidad intelectual suficiente para tomar la decisión. Por ello, la Corte concluye que el sujeto activo debe de ser un médico, puesto que es el único profesional capaz no sólo de suministrar esa información al paciente sino además de brindarle las condiciones para morir dignamente. Por ende, en los casos de enfermos terminales, los médicos que ejecuten el hecho descrito en la norma penal con el consentimiento del sujeto pasivo no pueden ser, entonces, objeto de sanción y, en consecuencia, los jueces deben exonerar de responsabilidad a quienes así obren. (Sentencia C-239/97, 1997 p. 6).

La que fue muy discutida incluso por el mismo Tribunal y que luego de su incorporación constitucional, no ha sido reglamentada; sin embargo, observamos que igualmente sigue siendo un tema que tiene mucho por transitar, pero aun con sus grandes diferencias e imprecisiones incluso conceptuales por los mismos juristas, esta se ha afianzado ampliando la eutanasia para que su práctica pueda ser realizada en menores que no deseen padecer los sufrimientos de una enfermedad o condición física determinada.

Finalmente, el último en sumarse a esta lista, es Canadá, quien ha legalizado la eutanasia en el año 2016, resolviendo a través de su Tribunal Supremo que la normativa que penalizaba la muerte asistida, en ese entonces 
era anticonstitucional, otorgándole al Parlamento un año para redactar una nueva ley; sin embargo, solo la limitaba a los enfermos terminales o con dolor insoportable y mayores de edad.

Existen otros países como Estados Unidos, donde la eutanasia es permitida en algunos Estados, como Washington, Montana, Oregon, Vermont y California, contando todas con la permisión al procedimiento del suicidio asistido como legal, ya que consideran la auto administración de dosis letales como un derecho de los enfermos terminales, no así la eutanasia activa. Y, aunque existan diferencias en la normatividad propia de cada Estado y en las definiciones según la forma en que se proceda, está permitida la muerte a petición del enfermo en condiciones indignas.

Otros países, en que está permitido el suicidio asistido o no está penalizado, son Alemania, Albania, Corea del Sur y Japón, en los que se facilita el suicidio asistido, siendo las normas penales poco persuasivas por el bajo estándar de penas previstas, por lo que resulta permisivo el suministrar medicamentos para lograr la muerte de las personas con enfermedades terminales o graves padecimientos, haciendo la salvedad que son los propios afectados los que deben tomarlos. No obstante, aun cuando el tema de la eutanasia haya sido legalmente autorizado incluso en estos países no deja de resultar controvertido, dado que lo que siempre estará en cuestionamiento, será la gran discusión de si esta es moral o no, es ética o no, resulta un alivio para el moribundo cuya vida se torna indigna o un alivio físico y económico para la familia y el Estado.

\section{LA EUTANASIA: ELECCIÓN O DERECHO}

La mayoría de juristas en estos países y otros en los que se han dado casos de eutanasia, aunque sin hacerlos de conocimiento público, centran sus discusiones en que la eutanasia resulta una violación palpable del derecho a la vida, la que en muchos casos, en los países en que no está permitida además se convertiría en un delito contra la vida, un homicidio, mientras que los que se inclinan a favor de la eutanasia, señalan que por sobre el derecho a la vida se encuentra el derecho a la libertad; por tanto, la eutanasia debe convertirse en una elección amparada en el derecho que ellos consideran el más importante, la libertad.

Asimismo, he advertido otro grupo de defensores de la eutanasia, que lo que piensa que debe prevalecer, al menos eso deduzco, es la dignidad, 
vivir con dignidad, significando que el vivir enfermo, adolorido o postrado, no es digno o no es parte de una vida digna. Mientras me pregunto, entonces un niño como los niños que padecían de trisomía 21 que eran lanzados del monte Taigeto, ahora también podrían ser lanzados desde la Costa Verde, para traer el ejemplo a la realidad peruana, ello resultaría terrible.

Otro ejemplo a meditar sería, que las personas que sufren de algún tipo de parálisis o se encuentran postradas ¿también merecerían ser libertadas de tan terrible indignidad? A través de cualquier tipo de eutanasia, la respuesta igualmente seguiría siendo no.

¿Por qué, los defensores de la igualdad de derechos de las mujeres, las personas en condiciones de vulnerabilidad y habilidades diferentes, son las que luchan por el aborto o la eutanasia, si justamente un ser que aún no puede defenderse es el más vulnerable y un ser postrado en cama y/o con una enfermedad incurable, se encuentra aún más expuesto a una condición de vulnerabilidad, acaso los intereses son distintos?, ¿acaso el móvil es otro?

Siento que, la persona que se encuentra enferma y no tiene las fuerzas suficientes, ni el ánimo para defenderse y luchar contra el malestar de su familia para que la consideren y no parezca un estorbo ¿se encontrarían en pleno uso de sus facultades mentales y voluntad lúcida para decidir morir?

Quienes deseen morir, porque no tienen una expectativa de vida más allá de la muerte podrían morir si lo desean, sin necesidad de despenalizar o variar la legislación, pues el suicidio no es penado, pero abrir una puerta o una ventana para que la gente que quiere vivir aun padeciendo alguna discapacidad o enfermedad muera, no resulta razonable, pues la sociedad y el mundo no se encuentran preparados para una igualdad y respeto de los derechos de los demás cuando estos dependen de un tercero, como la esposa, el esposo, los hijos o un desconocido, por lo que los móviles absolutamente subjetivos y muchas veces indemostrables, no podrían ser advertidos, conllevando ello a una desventura de la vida de las personas en esta condición.

Quizá me equivoque en mi apreciación, quizá haya gente que merezca morir porque lo desea, pero se debe proteger al más indefenso y sin duda alguna es mejor esa protección abierta a una permisión que podría llevar al irrespeto de lo más sagrado en el mundo que es la vida. 
Y, meditaba si la vida de las personas que sufren enfermedades mentales era digna o si su dolor espiritual por sus delirios de persecución que tanto susto parece causarles era justo y digno, entonces concluía en que la vida no es fácil para nadie, pero cada quien vive y disfruta lo mucho o poco que le toca vivir, pero vivir es el objetivo en la paz y en la guerra, en la salud y en la enfermedad, hasta que la muerte los separe y no la eutanasia. Pero podría equivocarme.

\section{LA MUERTE COMO FINAL DE LA VIDA}

No sabemos qué exista más allá de la muerte, dependiendo de nuestras creencias religiosas creeremos en nuestra espiritualidad trascendente y si no en que la vida acaba con el último suspiro.

En el colegio me enseñaron que la materia no se crea ni se destruye solo se transforma, lo dijo Lavoisier, en el siglo XVIII, partiendo de ese precepto, entonces la vida no acaba con el último suspiro del cuerpo, pues si nos movemos por energía, la energía saldrá de nuestro cuerpo físico pero se transformará en algo, no sé en qué pero, estoy segura que en algo.

Y, surge nuevamente la duda en mí, si la muerte es el final de la vida, ¿por qué acabar con ella?

\section{REFLEXIÓN}

A manera de reflexión diremos que la eutanasia existió desde tiempos muy remotos, teniendo fines selectivos justificados en degeneraciones físicas y malformaciones congénitas, cuyo concepto con el transcurrir del tiempo evolucionó conjuntamente con la revalorización del respeto a la vida, por lo que, poner a la muerte como una elección, aun con fines terapéuticos, compasivos, liberadores o de respeto a la dignidad ¿resulta coherente?

Si bien se dice que la vida es cíclica, estaríamos involucionando al permitir la muerte a elección, sea el motivo que fuera, pues así como se defiende al débil, indefenso o vulnerable, aún contra su voluntad como en los casos de violencia, porque no defender la vida de quien se encuentra indefenso y vulnerable ante la muerte, a la que encuentra como único camino. 


\section{CONCLUSIONES}

1.- La eutanasia es considerada una opción para finalizar la vida de una persona que viene sufriendo una enfermedad que no tiene cura o su padecimiento es tal, que la única solución es la muerte.

2.- Esta debe ser solo practicada por un médico que debe certificar la situación de salud del enfermo y dar fe de su sufrimiento.

3.- Existen múltiples polémicas sobre si corresponde la legalización o despenalización mundial de la eutanasia y si esta resulta moral o ética.

4.- De legalizarse la eutanasia, siendo un requisito elemental que la petición nazca de la propia voluntad de la persona a someterse a ella, esta no estaría viciada por su tristeza o sentimiento de desprotección y desamor, convirtiendo la legalización en una carta abierta para el homicidio.

5.- Se correría el riesgo de que se produzcan homicidios masivos de las personas de estratos sociales más bajos por falta de recursos económicos $\mathrm{u}$ homicidios por fines lucrativos como la herencia, en los estratos económicos más altos.

6.- Lo cierto y palpable es que es un tema de conciencia y enfoque personal muy profundo, basado en nuestro sentido de la vida.

7.- Si el derecho a la vida es el derecho fundamental sobre el que recae nuestra existencia y sobre el que reposan los demás derechos de los que gozamos, que nos permite ver la luz del día, el sol, la luna y las estrellas, mantener contacto con nuestros seres queridos y que ellos puedan advertir nuestra presencia, ¿existe una razón válida para acabar con ella?

\section{REFERENCIAS}

Ausín, F. J. \& Peña, L. (1998 Derecho a la Vida y Eutanasia: ¿Acortar la Vida o Acortar la Muerte? Anuario de Filosofía del Derecho XV (1998), pp. 13-30. Recuperado de: https://docplayer.es/8967511-Derecho-a-la-vida-y-eutanasia-acortarla-vida-o-acortar-la-muerte-f-jose-ausin-lorenzo-pena.html 
Grífols i Lucas, Víctor (2016). Eutanasia y Suicido Asistido. Cuadernos de la Fundación Victor Grifols i Lucas "Eutanasia y Suicidio asistido $N^{\circ} 41$. Fundación Víctor Grifols y Lucas.

Nombela Cano, C.; López Timoneda, F.; Serrano Ruiz-Calderón, J. M.; Postigo Solana, E.; Abellán Salort, J. C.; Prensa Sepúlveda, Lucía (2008). La Eutanasia: Perspectiva Ética, Jurídica y Médica.

Organización Mundial de la Salud (OMS).

Real Academia de la Lengua Española (RAE).

Rodríguez Casas, R. (2001). Eutanasia: aspectos éticos controversiales. Rev Med Hered [online]. 2001, vol.12, n.1, pp.32-36. ISSN 1018-130X. Recuperado de: http://www.scielo.org.pe/scielo.php?script=sci_ arttext\&pid=S1018-130X2001000100007\&lng=es\&tlng=es.

Tribunal Constitucional de Colombia, Sentencia C-239/97.

Vega J. (s.f). Eutanasia: Concepto, tipos, aspectos éticos y jurídicos. Actitudes del personal sanitario ante el enfermo en situación terminal. Recuperado de : https: / / docplayer.es/23885648-Eutanasia-concepto-tipos-aspectoseticos-y-juridicos-actitudes-del-personal-sanitario-ante-el-enfermoen-situacion-terminal.html

Fecha de recepción: 11 de noviembre de 2019

Fecha de aceptación: 29 de noviembre de 2019 